\title{
Orbitopterional Approach with Extradural Clinoidectomy for the Resection of a Tuberculum Sellae Meningioma: Adapting the Strategy to the Microsurgical and Pathological Anatomy
}

\author{
Jaafar Basma ${ }^{1}$ Vincent Nguyen ${ }^{1}$ Jeffrey Sorenson ${ }^{1}$ \\ ${ }^{1}$ Department of Neurosurgery, University of Tennessee, Memphis, \\ Tennessee, United States \\ J Neurol Surg B 2018;79(suppl S3):S261-S262.
}

\author{
L. Madison Michael II ${ }^{1}$
}

\begin{abstract}
Address for correspondence L. Madison Michael II, MD, Department of Neurosurgery, University of Tennessee, 847 Monroe Ave, Suite 427, Memphis, TN 38163, United States

(e-mail: mmichael@semmes-murphey.com).
\end{abstract}

\begin{abstract}
Keywords

- tuberculum

- sellae

- meningioma

- orbitopterional

- clinoid process

- optic nerve
\end{abstract}

Objectives To describe the orbitopterional approach with extradural clinoidectomy for the resection of a tuberculum sellae meningioma, with an emphasis on the microsurgical and pathological anatomy of such lesions.

Design After completing the orbitopterional craniotomy in one piece, the optic nerve is identified extradurally, unroofed, and the clinoid process resected. The falciform ligament is divided and the optic nerve is decompressed extradurally. Opening the frontotemporal dura exposes the tumor in the subfrontal region. The tumor is followed along the ipsilateral and contralateral optic nerves, and its dural tail is cut and coagulated at the level of the tuberculum. Care is taken to preserve the optic nerve perforators during the dissection. Photographs of the region are borrowed from Dr Rhoton's laboratory to illustrate the microsurgical anatomy.

Participants The surgery was performed by the senior author assisted by Dr. Jaafar Basma, neurosurgery fourth-year resident. The video was edited by Dr. Vincent Nguyen, neurosurgery third-year resident.

Outcome Measures Outcome was assessed with the extent of resection and visual symptoms.

Results A near-total resection of the tumor was achieved. A small part of tumor significantly adherent to the optic nerve was intentionally left behind. The patient had a stable vision examination postoperatively.

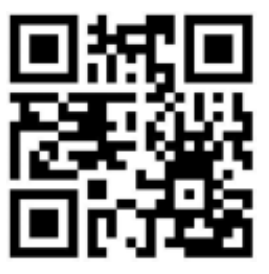

received

October 15, 2017 accepted

December 7, 2017

published online

February 14, 2018 www.thieme.com/skullbasevideos

www.thieme.com/jnlsbvideos
DOI https://doi.org/

10.1055/s-0038-1623523. ISSN 2193-6331.
๑) 2018 Georg Thieme Verlag KG
Stuttgart · New York

License terms

(c) $(1) \$$ 
Conclusions Understanding the microsurgical anatomy of the suprasellar region and the pathological anatomy of the tuberculum sellae meningioma is necessary to achieve a good resection of these tumors while preserving functionality of the optic apparatus. The orbitopterional approach with anterior clinoidectomy provides the appropriate access for such endeavor.

The link to the video can be found at: https://youtu.be/WtAP8uqSW0M.

\section{Conflict of Interest}

None.

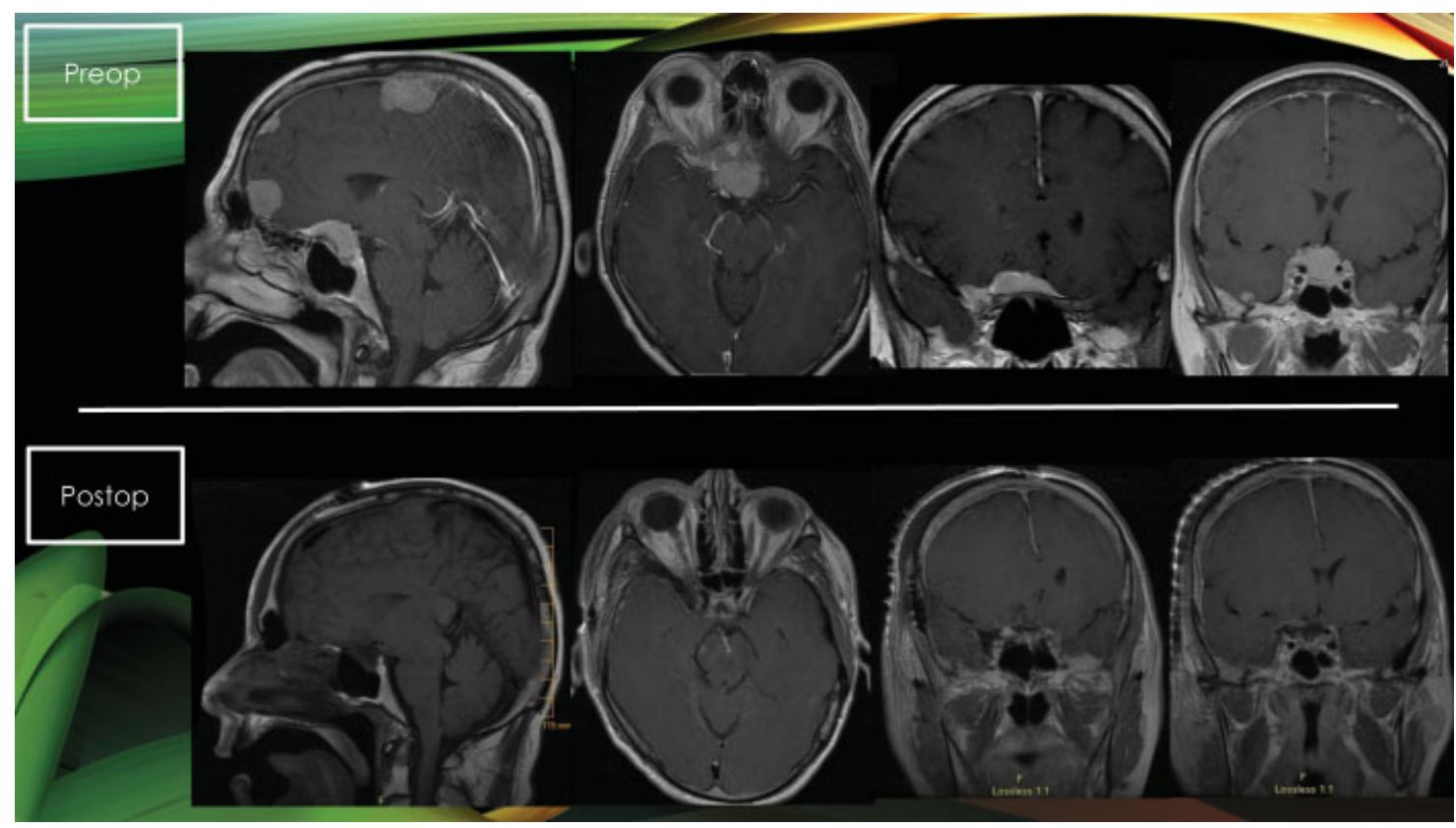

Fig. 1 Near-total resection of this tuberculum sellae meningioma was achieved as demonstrated by these pre- and postoperative imaging studies. Notice the enhancement of the right optic nerve preoperatively indicating likely invasion of the optic canal.

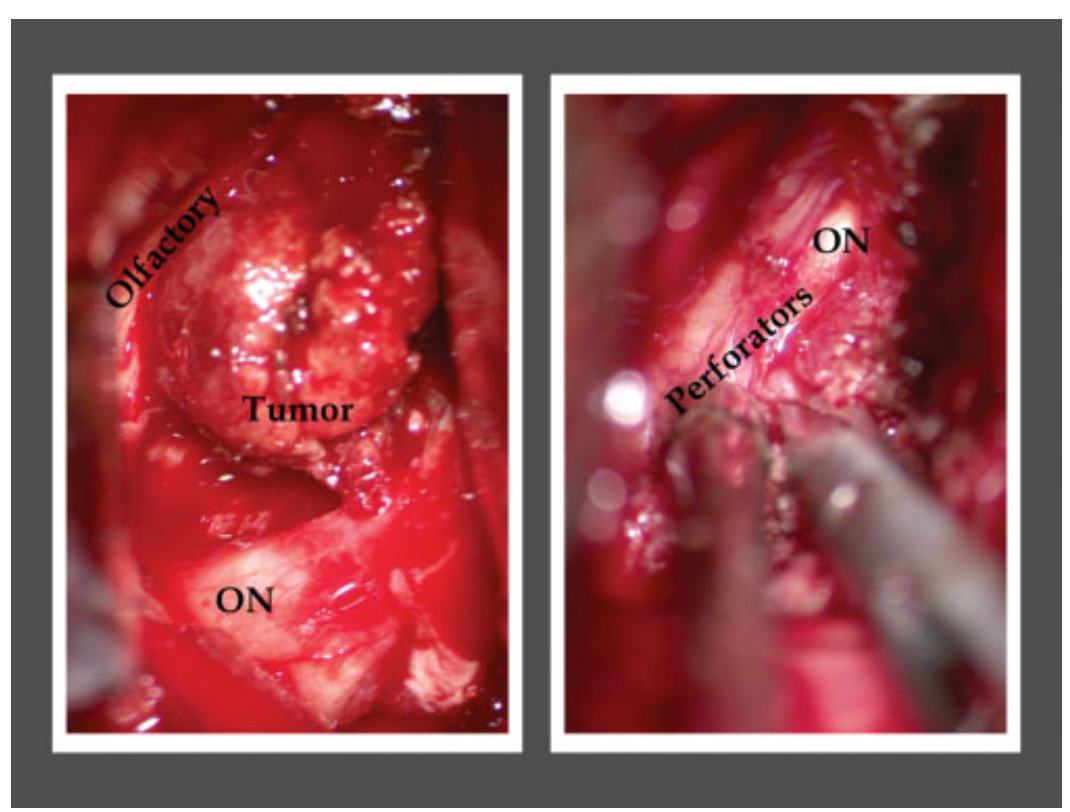

Fig. 2 This tuberculum sellae meningioma was near-totally resected through an orbitopterional approach with anterior clinoidectomy. Functionality of the optic apparatus was preserved by microsurgical preservation of the perforators as shown here. ON, optic nerve. 